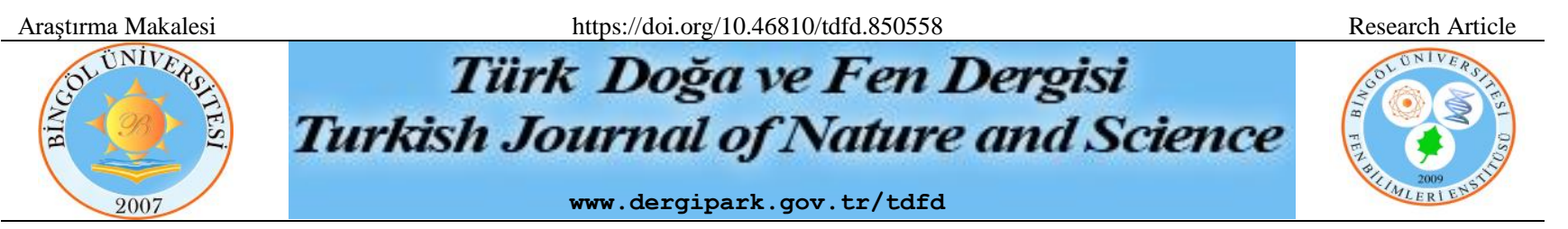

\title{
Üç Scorzonera L. Taksonunun Toprak Üstü ve Kök Kısımlarının Yağ Asidi Profillerinin Değerlendirilmesi
}

\author{
Güneş AK ${ }^{1 *}$, Gökhan ZENGİN ${ }^{1}$ \\ ${ }^{1}$ Selçuk Üniversitesi, Fen Fakültesi, Biyoloji Bölümü, Konya, Türkiye \\ Güneş AK ORCID No: 0000-0002-9539-0763 \\ Gökhan ZENGIN ORCID No: 0000-0001-6548-7823
}

*Sorumlu yazar: akguneselcuk@gmail.com

(Alınış: 30.12.2020, Kabul: 21.05.2021, Online Yayınlanma: 25.06.2021)

\section{Evaluation of The Fatty Acid Profiles of The Aerial and Root Parts of Three Scorzonera L. taxa}

Keywords Scorzonera, Fatty acid composition, Saturated fatty acids, Essential fatty acids

\begin{abstract}
The Scorzonera genus (Teke sakal1) is known as the source of numerous natural bioactive compounds. In the present study, it was aimed to determine the fatty acid compositions of oils obtained from the aerial parts and root parts of three Scorzonera taxa (S. hiericifolia Hayek., S. hispanica L. ve $S$. tomentosa L) by using gas chromatography technique. The levels of saturated fatty (SFA), monounsaturated fatty (MUFA) and polyunsaturated fatty acids (PUFA) were determined as $42.99-80.40 \%, 4.05-30.51 \%$ and $15.43-32,68 \%$, respectively. The highest SFA was detected in aerial parts of $S$. tomentosa and roots of $S$. hispanica. For MUFA, the highest percentage was observed in the aerial part and root part of the $S$. tomentosa. The highest PUFA level was found to be in S. hieraciifolia aerial part and the roots of S. tomentosa. It was observed that the SFA contents of the studied species were higher than MUFA and PUFA. In order to determine the differences of the species in terms of fatty acid content, to determine which fatty acids caused the differences from plants, and to determine the differences fatty acid compositions among the parts, obtained results were evaluated by multivariate statistical methods. Obtained results will be a starting point for new studies on on fatty acid compositions of the studied Scorzonera species.
\end{abstract}

korunması noktasında ana bileşenler konumundadır. Yağ asitlerinin yapısı ve bünyesinde ihtiva ettikleri bağlar biyolojik etkinlikleri noktasında belirleyici parametrelerdir. Bitkiler bünyelerinde bulundurdukları doymamış yağ asitleri ile sağlıklı yağlar olarak

\footnotetext{
Yağ asitleri insan diyetinin ayrılmaz bir parçası olup enerji metabolizması ile hücre membran bütünlüğünün

\section{GİRIŞ}
Anahtar
Kelimeler
Scorzonera,
Yağ asidi
komposizyonu,
Doymuş yağ
asitleri,
asitleri

Esansiyel yă

Öz: Scorzonera cinsi (Teke Sakalı), çok sayıda doğal biyoaktif bileşiğin kaynağı olarak bilinir. Mevcut çalışmada, üç Scorzonera taksonunun ( $S$. hiericifolia Hayek., S. hispanica L. ve $S$. tomentosa L.) toprak üstü ve kök kısımlarından elde edilen yağların yağ asidi komposizyonlarının gaz kromatografi cihazı kullanılarak belirlenmesi amaçlanmıştır. Doymuş (SFA), tekli doymamış (MUFA) ve çoklu doymamış (PUFA) yağ asitlerinin seviyeleri sırasıyla \% 42,99-80,40; \% 4,0530,51 ve \% 15,43-32,68 olarak belirlenmiştir. En yüksek SFA içerikleri S. tomentosa'nın toprak üstü kısmı ile $S$. hispanica'nın kök kısımlarında tespit edilmiştir. MUFA bakımından en yüksek yüzde $S$. tomentosa'nın toprak üstü ve köklerinden elde edilen yağda belirlenmiştir. En yüksek PUFA seviyesi $S$. hieraciifolia'nın toprak üstü ile $S$. tomentosa'nın kökünde gözlenmiştir. Çalışılan türlerin SFA içerikleri MUFA ve PUFA içeriklerinden daha yüksektir. Türlerin yağ asidi içeriği açısından farklılıklarını belirlemek, bitkilerden farklılığa hangi yağ asitlerinin neden olduğunu belirlemek ve bitki kısımları arasındaki yağ asidi bileşimlerinin farklılıklarını belirlemek için elde edilen sonuçlar çok değişkenli istatistiksel yöntemlerle değerlendirilmiştir. Çalışmamızın sonuçları belirtilen Scorzonera türlerinin yağ asidi kompozisyonları üzerine yapılacak olan yeni çalışmalara bir başlangıç noktası oluşturacaktır.
\end{abstract}


nitelendirilmektedir (1). Bitkilerdeki toplam lipit ve yăg asidi bileşimlerinin içeriği, bitkisel yağın besinsel değerinin yorumlanması açısından önemli bir göstergedir (2). Esansiyel yağ asitleri insan sağlığı açısından önemlidir. İnsanlar tarafından sentezlenemeyen bu yağ asitleri diyet yoluyla alınmak zorunda olup başta beyin gelişimi ve normal fizyolojik fonksiyonların devamı için gereklidir. Çeşitli çalışmalar yağ asitleri ile çeşitli hastalıklar arasındaki ilişkiyi açıklamaktadır. Örneğin, tekli/çoklu doymamıs yağ asitlerinin tüketimi kolesterolü ve dolayısıyla miyokardiyal hastalık riskini düşürmede faydalıdır (3). Ayrıca çoklu doymamış yağ asitleri (PUFA'lar) otoimmün rahatsılıklar, sinir hastalıkları, antiinflamatuar, antitrombotik, ateroskleroz, hipolipidemik, antiaritmik, vazodilatör, diyabet gibi diğer birçok hastalıkların tedavisinde ve önlenmesinde ve lipid peroksidasyon sürecinin iyileştirilmesinde önemli rol oynar $(4,5)$. Bu nedenle son yıllarda yağ asitleri ve bunların sağlık üzerine olan özelliklerine olan ilgi artmaktadır. Ancak, artan nüfus ve besinsel ihtiyaçlar değerlendirildiğinde günümüzde sağlıklı yeni yağ kaynaklarına ihtiyaç vardır. Bu nedenle, yeni ve güvenilir yă̆ kaynaklarının belirlenmesi bilim dünyası için ilgi çekici bir konumdadır (6).

Asteraceae (Compositae) familyası, 1.900'den fazla cins ve 32,000'den fazla türe sahip, en büyük çiçekli bitki familyası olarak bilinmektedir. Scorzonera L. cinsi, dünyanın dört bir yanında yaygın olarak dağılım gösteren ve yaklaşı1k 160 türden oluşan Asteraceae ailesinin bir üyesidir. Türkiye bu cins için, 31'i endemik 54 tür ile, bir merkez olarak kabul edilmektedir (7). Scorzonera üyeleri ülkemizde yörelere göre farklılık göstermekle beraber genel olarak "teke sakalı" olarak bilinirler. Asteraceae familyasına ait üyeler, genellikle bitkisel çaylar, çeşitli baharatlar, tatlandırıcılar olarak çeşitli amaçlarla kullanılmaktadır ve bu özellikleriyle familya, ekonomik açıdan oldukça önemli konuma sahiptir. Birçok Scorzonera türü baharat, sebze veya geleneksel tıpta kullanılmaktadır (8). Scorzonera türlerinin, birçok ülkede geleneksel olarak analjezik, antiromatizmal, antelmintik, idrar söktürücü, yara iyileştirici, kısırlık, gut, akciğer ödemi, ishal, mide ülseri, malign mide kanseri, hipertansiyon ve yılan 1sırıklarının tedavisinde kullanıldığı çeşitli çalışmalar ile ortaya konulmuştur $(7,9,10)$. Çalışma kapsamında kullanılan, $S$. tomentosa bitkisi Türkiye'ye özgü çok yıllık bir bitkidir ve halk arasında genellikle "Alabent veya Alman sakızı" isimleriyle bilinmektedir. Kök kısımlarında içerdiği lateks içeriği nedeniyle geleneksel tıpta yara iyileştirme, analjezik, antiromatizmal, antihelmintik olarak kullanılmaktadır (11-13). $S$. hieraciifolia bitkisi, Türkiye'ye ait endemik bir türdür ve geleneksel tıpta, antiromatik, ishal, mide ülseri, hipertansiyon, gut gibi birçok tedavide kullanılan bitki, halk arasında "Yılan kökü" ismiyle bilinmektedir (7). S. hispanica bitkisi halk arasında genellikle "Kara salsifiye veya Sakız otu" isimleriyle bilinmektedir ve özellikle kök kısımları halk hekimliğinde sindirimin düzenlenmesi ve terlemeyi artırmak için diüretik ajan olarak kullanılmaktadır. Bunlara ek olarak, S. hispanica'nın kök kısımları Batı Avrupa'da sebze olarak yaygın şekilde kullanılmaktadır $(8,14)$.
Bu çalışmada üç Scorzonera taksonunun (S. hiericifolia, $S$. hispanica ve $S$. tomentosa) toprak üstü ve kök kısımlarından elde edilen yağların yağ asidi komposizyonlarının gaz kromatografi tekniği kullanılarak belirlenmesi amaçlanmıştır. Ele geçen sonuçlar bu cins üzerine yeni bakıș açılarının kazandırılmasına ve bu cinsin yeni yağ kaynakları olarak değerlendirilmesine bilimsel bir temel teşkil edecektir.

\section{MATERYAL VE METOT}

\subsection{Bitki Örneklerinin ve Bitkilerden Yağın Eldesi}

Çalışmamızda kullanılan Scorzonera cinsine ait bitkiler, 2019 yılında Konya'da yapılan arazi çalışması sırasında toplanmıştır. Bitkisel materyallerin taksonomik olarak tanımlanması, Selçuk Üniversitesi Fen Fakültesi Biyoteknoloji Bölümü Öğretim Üyesi Prof. Dr. Evren Yildıztugay tarafindan yapılmıştır. (Herbaryum no:EY3003 (S. hieraciifolia), EY-3019 ( S. tomentosa ), EY3031 (S.hispanica)).

Öğütülerek toz haline getirilmiş olan $10 \mathrm{~g}$ bitkisel materyal, Sokslet ekstraktörü kullanılarak $60^{\circ} \mathrm{C}^{\prime} \mathrm{de}$ 6-8 saat süreyle çözücü olarak kullanılan petrol eteri ile özütleme işlemi gerçekleştirildi. Ekstraksiyonu takiben petrol eteri evaporatör kullanılarak uzaklaştırıldı ve ele geçen yağ metil esterlerin elde edilmesinde kullanıldı

Metil esterlerinin elde edilmesi için yağ örneklerinden, 0,1-0,2 g balonlara aktarıldı ve üzerlerine $4 \mathrm{~mL} \% 2^{\prime}$ lik $\mathrm{NaOH}$ çözeltisi eklendi ve sabunlaşmanın gerçekleştirilmesi için 10 dakika kaynatıldı. Sabunlaşma işleminin tamamlanmasının ardından $5 \mathrm{~mL} \mathrm{BF}_{3}$ eklendi ve 5 dakika kaynatıldı. Daha sonra karışım üzerine $2 \mathrm{~mL}$ n-heptan eklendi ve 1 dakika kaynatıldı. Bu işlemleri takiben son olarak $4 \mathrm{~mL}$ doymuş $\mathrm{NaCl}$ çözeltisinden eklendi ve balonlar iyice karıştırıldıktan sonra oluşan fazların ayrımı için karışım ayırma hunisine aktarıldı. Alt kısımda kalan sulu kısım atıldıktan sonra üst faz viallere aktarıldı ve analiz edilinceye kadar $-20^{\circ} \mathrm{C}$ de saklandı.

\subsection{Yağ Asitlerinin Gaz Kromatografi Cihazında Analizi}

Gaz kromatografik analizler HP (Hewlett Packard) Agilent marka $6890 \mathrm{~N}$ model Flame Ionization Detector: Alev iyonlaştırma dedektörü) dedektörlü ve otomatik injektörlü gaz kromatograf cihazı ile gerçekleştirildi ve analizlerde 100 metrelik HP-88 kapiller kolon kullanıldı. Kolona sıcaklık programı uygulandı ve kolon başlangıç sicaklığ $1 \quad 60^{\circ} \mathrm{C}$ olarak ayarland $1.60^{\circ} \mathrm{C}$ 'de 1 dakika beklendikten sonra sıcaklık dakika $20^{\circ} \mathrm{C}$ artırılarak 190 ${ }^{\circ} \mathrm{C}$ 'ye ulaştı ve bu derece 60 dakika bekletildi. Daha sonra sıcaklık dakika $1{ }^{\circ} \mathrm{C}$ artırılarak $220{ }^{\circ} \mathrm{C}$ ulaştı ve bu sicaklıkta $10 \mathrm{dk}$ bekletildi. Böylece analizler 107 dakika'da tamamlandı. Enjektör bloğu ve dedektör sicaklığ 1 sirasıyla $250{ }^{\circ} \mathrm{C}$ ve $280{ }^{\circ} \mathrm{C}$ olarak ayarland 1 . Enjeksiyon hacmi $1 \mu$ lolarak ayarland 1 ve split oranı ise 40:1'dir. Yağ asitlerinin tanımlanması için Accu ve Alltech firmalarından alınan standard yağ asitlerinin alıkonma zamanları ile örneklerde gelen yağ asitlerinin karşılaştırılmıştır. Analizler üç tekrarlı olarak yapıldı ve 
kromatogramlardaki piklerin yüzde alanların aritmetik ortalamaları ve standart sapmaları hesaplanarak verildi.

\section{3. İstatistiksel Değerlendirme}

Sonuçlar, üç tekrarın ortalama \pm standart sapmaları şeklinde verildi. Elde edilen yağ asitlerinin istatistiksel değerlendirilmesinde çoklu varyans analiz sistemi (ANOVA) kullanılmıştır. Türlerin yağ asidi içerikleri açısından değişkenliklerinin belirlenmesi için, temel bileșen analizi (PCA) kullanıldı, türlere ait kısımlar arasında birbirine yakın yağ asidi komposizyonlarının belirlenmesi için kümeleme analizi (HCA) ve bitkilerden gelen farklılığın hangi yağ asitlerinden kaynaklandı̆̆ını belirlemek için, kısmi en küçük kareler-ayırt edici analizi (PLS-DA) yapıldı. Bu analizler, R- 3.6.2 yazılımında gerçekleştirildi.

\section{BULGULAR}

Çalışma kapsamında kullanılan üç Scorzonera türünün toprak üstü ve kök kısımlarına ait yă̆ asidi kompozisyonlarımın analizleri sonucunda, içeriklerinde toplam 12 adet yağ asidi olduğu belirlenmiştir. Elde edilen sonuçlar Tablo 1'de verilmiştir. Analiz sonucu elde edilen yağ asitlerinin karbon sayılarının 12 ile 18 arasında değişmektedir. Araştırılan Scorzonera türlerinde majör yağ asidi genellikle C 16:0 (palmitik asit) olmakla birlikte bitkinin farklı kısımlarında, majör yağ asidinin C 14:0 (miristik asit) olduğu gözlenmiştir.

Tablo 1. Scorzonera türlerinin yă̆ asidi içerik sonuçları (\%).

\begin{tabular}{|c|c|c|c|c|c|c|}
\hline $\begin{array}{l}\text { YAĞ } \\
\text { ASİTLERI }\end{array}$ & $\begin{array}{l}S . \\
\text { hieracifolia- } \\
\text { toprak üstü }\end{array}$ & $\begin{array}{l}S . \\
\text { hieracifolia- } \\
\text { kök }\end{array}$ & $\begin{array}{l}S . \\
\text { hispanica- } \\
\text { toprak üstü }\end{array}$ & $\begin{array}{l}S . \\
\text { hispanica- } \\
\text { kök }\end{array}$ & $\begin{array}{l}S . \\
\text { tomentosa- } \\
\text { toprak üstü }\end{array}$ & $\begin{array}{l}S . \\
\text { tomentosa- } \\
\text { kök }\end{array}$ \\
\hline C 12:0 & $1,01 \pm 0,16$ & $0,22 \pm 0,04$ & $1,58 \pm 0,03$ & $1,98 \pm 0,06$ & $1,42 \pm 0,07$ & $0,14 \pm 0,03$ \\
\hline C 14:0 & $14,39 \pm 0,05$ & $27,73 \pm 0,07$ & $22,64 \pm, 04$ & $49,52 \pm 0,83$ & $24,41 \pm 0,11$ & $14,21 \pm 0,01$ \\
\hline C 15:0 & $0,44 \pm 0,04$ & $0,40 \pm 0,01$ & $0,57 \pm 0,01$ & $0,24 \pm 0,01$ & $0,07 \pm 0,01$ & $0,56 \pm 0,036$ \\
\hline C 16:0 & $37,82 \pm 0,13$ & $36,90 \pm 0,28$ & $32,69 \pm 0,01$ & $26,95 \pm 0,68$ & $40,88 \pm 0,24$ & $23,16 \pm 0,92$ \\
\hline $\begin{array}{l}\text { C 17:0 } \\
\end{array}$ & 01 & $0,60=$ & $0,07+4$ & $0,98 \pm 0,02$ & $3,26 \pm 0,06$ & $1,79 \pm 0,11$ \\
\hline 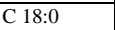 & $3,90 \pm 0,01$ & $1,81 \pm 0,07$ & $4,30 \pm 0,02$ & $0,74 \pm 0,02$ & $4,80 \pm 0,07$ & $3,13 \pm 0,13$ \\
\hline$\overline{\mathbf{\Sigma S F A}^{*}}$ & $57,76 \pm 0,40$ & $67,66 \pm 0,49$ & $02,01 \pm 0,10$ & $80,40 \pm 1,61$ & $74,84 \pm 0,57$ & $42,99 \pm 1,23$ \\
\hline C 15:1 $\omega 5$ & $1,34 \pm 0,09$ & $0,43 \pm 0,24$ & $0,10 \pm 0,01$ & $0,69 \pm 0,07$ & $0,83 \pm 0,01$ & $0,49 \pm 0,01$ \\
\hline C 16:1 $\omega 7$ & $0,53 \pm 0,08$ & $0,41 \pm 0,01$ & $0,13 \pm 0,01$ & $0,11 \pm 0,01$ & $0,67 \pm 0,03$ & $0,19 \pm 0,01$ \\
\hline C 17:1 $\omega 8$ & $0,46 \pm 0,09$ & $0,16 \pm 0,04$ & $0,50 \pm 0,01$ & $0,37 \pm 0,01$ & $0,74 \pm 0,03$ & $0,34 \pm 0,02$ \\
\hline C $18: 1 \omega 9$ & $7,27 \pm 0,12$ & $8,71 \pm 0,08$ & $8,63 \pm 0,02$ & $2,88 \pm 0,01$ & $7,51 \pm 0,04$ & $29,50 \pm 0,52$ \\
\hline IMUFA $^{*}$ & $9,59 \pm 0,39$ & $9,70 \pm 0,12$ & $9,35 \pm 0,02$ & $4,05 \pm 0,08$ & $9,75 \pm 0,04$ & $30,51 \pm 0,55$ \\
\hline C 18:2 $\omega 6$ & $13,98 \pm 0,13$ & $18,55 \pm 0,19$ & $19,31 \pm 0,20$ & $11,75 \pm 0,01$ & $4,62 \pm 0,04$ & $19,72 \pm 0,80$ \\
\hline C $18: 3 \omega 6$ & $4,05 \pm 0,04$ & $1,39 \pm 0,09$ & $3,05 \pm 0,25$ & $2,69 \pm 0,05$ & $5,55 \pm 0,61$ & $1,07 \pm 0,07$ \\
\hline C $18: 3 \omega 3$ & $14,65 \pm 0,17$ & $2,73 \pm 0,12$ & $5,71 \pm 0,03$ & $1,12 \pm 0,10$ & $5,26 \pm 0,01$ & $5,70 \pm 0,07$ \\
\hline IPUFA ${ }^{*}$ & $32,68 \pm 0,35$ & $22,66 \pm 0,40$ & $28,07 \pm 0,48$ & $15,55 \pm 0,16$ & $15,43 \pm 0,66$ & $26,49 \pm 0,94$ \\
\hline EUFA ${ }^{*}$ & $42,26 \pm 0,38$ & $32,35 \pm 0,28$ & $37,42 \pm 0,49$ & $19,60 \pm 0,24$ & $25,17 \pm 0,59$ & $57,00 \pm 1,21$ \\
\hline$\overline{\Sigma E F A}{ }^{*}$ & $28,63 \pm 0,04$ & $21,27 \pm 0,07$ & $25,02 \pm 0,23$ & $12,87 \pm 0,09$ & $9,88 \pm 0,05$ & $25,42 \pm 0,73$ \\
\hline
\end{tabular}

SFA (Doymuş yağ asitleri), MUFA (Tekli doymamış yă asitleri), PUFA (Çoklu doymamı̧ yağ asitleri), UFA (Doymamış yağ asitleri), EFA (Esansiyel yağ asitleri)

Çalışmamızda kullanılan Scorzonera türlerine ait toprak üstü ve kök kısımlarının içerdiği toplam doymuş yağ asidi (SFA) miktarları değerlendirildiğinde S.hieraciifolia bitkisi için majör yağ asidi olarak, her iki kısım içinde palmitik asit olduğu tespit edilmiştir. $\mathrm{Bu}$ türe ait palmitik asit yüzdeleri, toprak üstü için

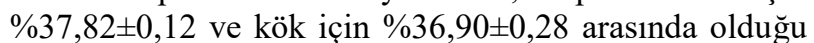

gözlenmiştir. SFA bakımından bu bitki için palmitik asitten sonra en yüksek yüzdeye sahip yă asidi toprak üstü için $\% 14,39 \pm 0,05$ ve kök için $\% 27,73 \pm 0,07$ değerleriyle miristik asit olduğu görülmüştür. $S$. hispanica bitkisi için içerdiği SFA oranı incelendiği toprak üstü ve kökte oranların değiştiği görülmüş ve

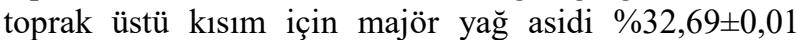
değeriyle palmitik asit iken, kök için majör yağ asidi $\% 49,52 \pm 0,08$ değeri ile miristik asit olduğu gözlenmiştir. S. tomentosa için SFA değerleri incelendiğinde toprak üstü ve kök kısımları için bu değerler sırasıyla $74,84 \pm 0,57$ ve $42,99 \pm 1,23$ bulunmuştur ve majör doymuş yağ asidi olarak palmitik asit daha sonra da mirisitik asit geldiği gözlenmiştir (Şekil 1)

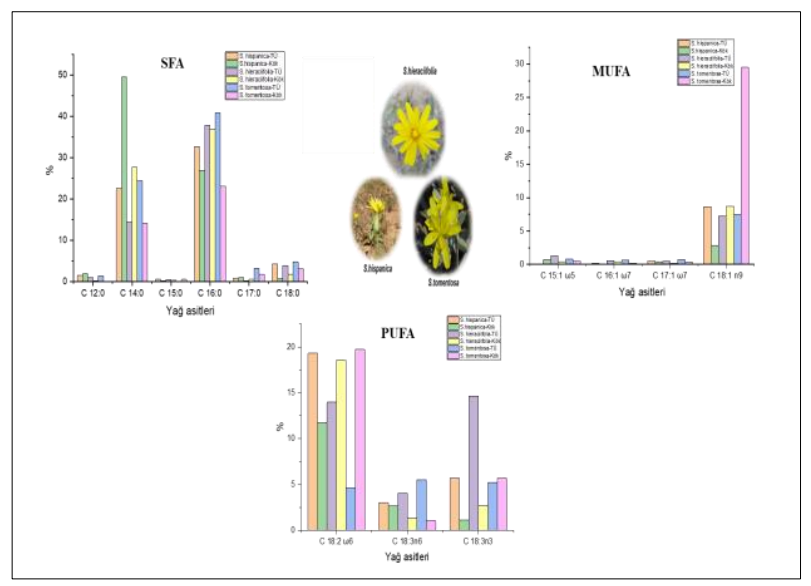

Şekil 1. Scorzonera türlerinin SFA, MUFA, PUFA içerik sonuçları.

Tekli doymamış yağ asitleri (MUFA) içerikleri incelendiğinde her 3 bitkide de MUFA içeriğinin büyük bir kısmını oleik asitin oluşturduğu görülmüştür. MUFA içeriği için yüzde değerler $\% 2,88 \pm 0,01$ ile $\% 29,50 \pm 0,52$ arasında değişkenlik göstermiştir. Bu değerlerden en yüksek yüzdeye sahip bitki $S$. tomentosa'ya ait kök kısmı olurken en düşük yüzdeye sahip bitki $S$. hispanica'ya ait kök kısmı olduğu görülmüştür. MUFA değerleri içerisinde diğer bitkilerin kısımlarına ait yağ asit içerikleri düşük seviyelerde tespit edilmiştir (Şekil $1)$.

Araştırılan Scorzonera türlerine ait çoklu doymamış yağ asitleri (PUFA) içeriğinin büyük bir yüzdesini C 18:2 $\omega 6$ linoleik asit oluşturmaktadır. Linoleik asit yüzdeleri türlerin farklı kısımlarında \%4,62 $\pm 0,04$ - \%19,72 $\pm 0,80$ değerleri arasında değişmektedir. Bitkilerden en yüksek linoleik asit içeriğine $S$. tomentosa'nın kök kısmında ve en düşük linoleik asit miktarı ise $S$. tomentosa'nın toprak üstü kısmında gözlenmiştir. Diğer bir doymamış yağ asidi olan linolenik asit için bu değerler \%1,12 $\pm 14,65$ arasında değiştiği görülmüştür. Linolenik asit içeriği en yüksek oranda $S$. hieraciifolia'ya ait toprak üstü kısmından elde edilirken en düşük içeriğe sahip örnek ise S. hispanica'nın kökü olarak belirlenmiştir (Şekil 1).

Scorzonera türlerine ait yağ asidi bileşimlerinin incelenmesine dair literatür taraması yapıldığında yeterli düzeyde bilgi olmamakla birlikte $S$. paradoxa üzerine yapılan bir yă asidi kompozisyonu çalışmasında, çalışmamızı destekler nitelikte doymuş yağ asidi miktarı 
diğer yağ asitlerine oranla daha yüksek miktarda olduğu tespit edilmiştir (15).

Çalışılan Scorzonera türlerine ait toprak üstü ve kök kısımlarının farklı yağ asidi kompozisyonlarına sahip olmaları sebebiyle, elde edilen verilerin daha kapsamlı yaklaşımların uygulanmasını gerektirmiştir. Bu noktadan hareketle yağ asidi sonuçları bitkiler ve kısımları için ileri istatistik testleriyle yorumlanmıştır. $\mathrm{Bu}$ testler öncelikle çalışılan Scorzonera türlerin toprak üstü ve kök kısımları arasında yağ asidi kompozisyonları bakımından farkı daha net görme imkanı sağlarken ilave olarak çalışılan türlerin ayrımında hangi yağ asitlerinin daha etkili olabileceğini yorumlamamıza imkan sağlamaktadır. $\mathrm{Bu}$ nedenle ilk olarak, Scorzonera türlerini ayırt etmek için temel bileşen analizi kullanılmıştır ve sonuçlar Şekil 2 'de verilmiştir. Sonuçlar, türler arasındaki maksimum değişkenliğe sahip boyutların belirlenmesi için bileşen sayısının seçilmesinde en yaygın kullanılan "Kaiser kuralı" na göre yorumlanmıştır. Bu kurala göre öz değeri 1'den büyük ve toplam değişkenlerin \%80'inden fazlasına katkıda bulunan özdeğer değerlendirilebilir. Buna göre elde edilen sonuçlar değerlendirildiğinde, dört boyutta dağılım gözlenmiştir ve bu dört boyut toplam değişkenlerin \%93'ünü kapsamaktadır (Şekil 2). Boyutların ayrımına en fazla katkı sağlayan parametreler Şekil 2'de verilmiştir. Bu bağlamda, boyutlardaki farklılığa neden olan majör yağ asitleri PC1 için, C 18:3n6 ve C 18:2w6, PC2 için, C 14:0 ve C 18:3n3, PC3 için, C: $17: 0$ ve C 18:2n6 ve PC4 için, C 12:0 ve C 16:1w7 ile bağlantılı olduğu yorumlanmıştır. $\mathrm{Bu}$ sonuçlar açık bir şekilde boyutların dağılımında doymuş yağ asitlerinin daha etkili parametreler olduğunu göstermiştir. Boyutlar ve çalışılan türler ve kısımları ile birlikte değerlendirildiğinde türlerin ve kısımların farklı bir dağılım kompozisyonuna sahip olduğu görülmüştür (Şekil 2). Boyutlar içerisindeki dağılım, türler ve kısımlar için yeteri kadar net olmadığı için kümeleme analizi yapılmıştır ve bunun sonucunda birbirine yakın yağ asidi içeriğine sahip türler 4 grupta toplanmıştır (Şekil 3).

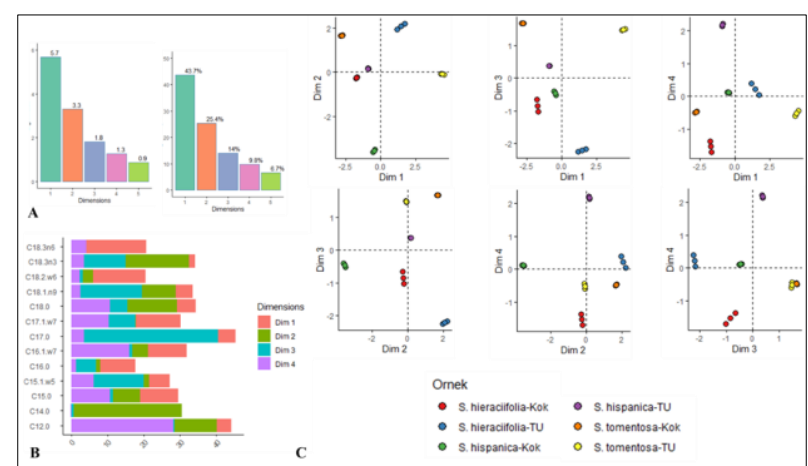

Şekil 2. Scorzonera türlerinin yă̆ kompozisyonlarının temel bileşen ve küme analizleri. C: PCA boyutlarının açıklanan varyans ve özdeğer yüzdesi. B. PCA'nın ilk dört boyutuna biyoaktivitelerin katkısı. C. Tüm örneklerin dağılım grafiği.

Bitkilere ait toprak üstü ve kök kısımlarındaki ayrımın hangi yağ asidi bileşeninden geldiğinin anlaşılması için PLS-DA analizi yapıldı ve elde edilen VIP puanları Şekil 4'de verilmiştir. Her bir bitkiye ait toprak üstü ve kök kısımları kendi arasında değerlendirildi ve kısımlar arasındaki farklılığın 1 değerinden büyük olan yăg asitlerinden geldiği görülmüştür (Şekil 4).

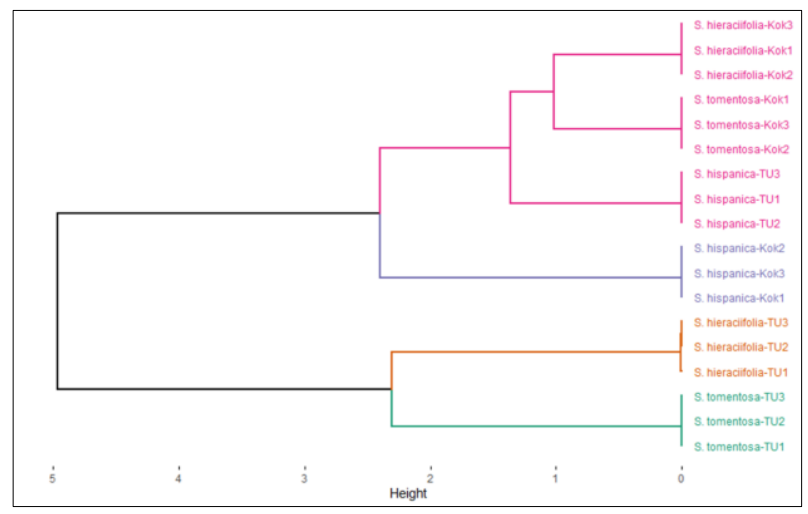

Sekil 3. Türlere ait kısımların kümeleme analizi.

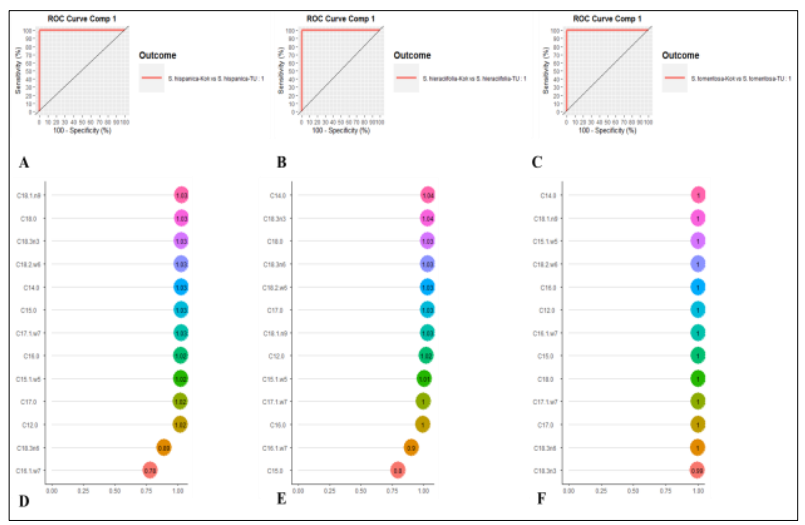

Sekil 4. Bitkilerin her birine ait toprak üstü ve kök kısımlarının PLSDA sonuçları. A-C: parçalar arasındaki ayrımı gösteren ROC curve DF. VIP puanlama sonuçları.

\section{SONUÇ}

Çalışmamız kapsamında tüm türlerin yağ asidi içerikleri incelendiğinde toplam SFA'ların, MUFA VE PUFA'lara göre daha yüksek seviyede oldukları belirlenmiştir. Ayrıca türler arasında toplam PUFA içeriğinin MUFA içeriklerinden fazla olduğu gözlenmiștir. Bu verilerden hareketle Scorzonera türlerinin yağ asidi kompozisyonlarının büyük bir kısmını doymuş yağ asitlerinin oluşturduğu belirlenmiştir. Çalışmamız ile üç Scorzonera türünün yağ asidi kompozisyonu ile literatüre yeni veriler sağlanacak ve bu türler üzerine yapılacak yeni çalışmalarda yeni fikirlerin doğmasına yol açacaktır.

\section{KAYNAKLAR}

[1] Czumaj A, Śledziński T. Biological role of unsaturated fatty Acid desaturases in health and disease. Nutrients. 2020;12(2):356.

[2] Xiao L, Mjøs SA, Haugsgjerd BO. Efficiencies of three common lipid extraction methods evaluated by calculating mass balances of the fatty acids. J Food Comp Anal. 2012;25(2):198-207.

[3] Zyriax BC, Windler E. Dietary fat in the prevention of cardiovascular disease-a review. Eur J Lipid Sci Technol. 2000;102(5):355-65. 
[4] Anese M, Bot F, Panozzo A, Mirolo G, Lippe G. Effect of ultrasound treatment, oil addition and storage time on lycopene stability and in vitro bioaccessibility of tomato pulp. Food Chem. 2015;172:685-91.

[5] Ramadan MF, Sharanabasappa G, Seetharam Y, Seshagiri M, Moersel J-T. Characterisation of fatty acids and bioactive compounds of kachnar (Bauhinia purpurea L.) seed oil. Food Chem. 2006;98(2):359-65.

[6] Chow CK. Fatty acids in foods and their health implications: CRC press; 2007.

[7] Sarı A, Şahin H, Özsoy N, Çelik BÖ. Phenolic compounds and in vitro antioxidant, antiinflammatory, antimicrobial activities of Scorzonera hieraciifolia Hayek roots. South Afr J Bot. 2019;125:116-9.

[8] Erden Y, Kırbağ S, Yılmaz Ö. Phytochemical composition and antioxidant activity of some Scorzonera species. Proc Natl Acad Sci India Sect B Biol Sc. 2013;83(2):271-6.

[9] Akkol EK, Šmejkal K, Kurtul E, Ilhan M, Güragac FT, İşcan GS, et al. Inhibitory activity of Scorzonera latifolia and its components on enzymes connected with healing process. J Ethnopharmacol. 2019;245:112168.

[10] Sarı A, Özbek B, Özgökçe F. Antimicrobial activities of two Scorzonera species growing in Turkey. Asian J Chem. 2009;21(6):4785-8.

[11] Acikara O, Çitoğlu G, Çoban T. Phytochemical Screening and Antioxidant Activities of Selected Scorzonera Species. Turk J Pharm Sci. 2013;10(3):453-62.

[12] Acıkara Ö, Citoglu GS, Gencler-Ozkan A. Qualitative and quantitative analysis of phenolic acids in Scorzonera tomentosa L. Turk J Pharm Sci. 2013;10(1):1-8.

[13] Korkmaz M, Alpaslan Z. Ergan Dağı ErzincanTürkiye'nın etnobotanik özellikleri. Bağbahçe Bilim Dergisi. 2015;1(3):1-31.

[14] Granica S, Lohwasser U, Jöhrer K, Zidorn C. Qualitative and quantitative analyses of secondary metabolites in aerial and subaerial of Scorzonera hispanica L.(black salsify). Food Chem. 2015;173:321-31.

[15] Nasseri MA, Bigy SS, Allahresani A, Malekaneh M. Assessment of antioxidant activity, chemical characterization and evaluation of fatty acid compositions of Scorzonera paradoxa Fisch and CA Mey. Jundishapur J Nat Pharm Prod 2015;10(4):e19781. 